\title{
As práticas pedagógicas das Irmãs Militão: um misto de medo, amor e respeito por duas professoras leigas do interior da Bahia
}

\section{The pedagogical practices of the Militão Sisters: a mixture of fear, love and respect for two lay teachers from the countryside of Bahia}

\author{
Luzinete Moreira da Silva \\ Orcid: https://orcid.org/0000-0001-7105-8638 \\ Programa de Pós-graduação em Educação - PPED, Universidade Tiradentes - \\ UNIT, Aracaju-SE, Brasil, luzmoreira2009@gmail.com \\ Cristiano de Jesus Ferronato \\ Orcid: https://orcid.org/0000-0003-2735-6595 \\ Programa de Pós-graduação em Educação - PPED, Universidade Tiradentes - \\ UNIT, Aracaju-SE, Brasil, cristiano_jesus@unit.br
}

Recebido em 21/08/2020 - Aprovado em 26/08/2020

\begin{abstract}
Resumo
O objetivo deste estudo é analisar as práticas pedagógicas das Irmãs Militão, duas professoras leigas do Município de Senhor do Bonfim-BA. Partindo dos pressupostos da História Pública Digital sob o embasamento de autores como Carvalho (2016), Lima (2015) e Porto e Santos ( 2014), utilizamos como fontes de pesquisa, comentários de publicações na rede social Facebook. As análises foram feitas embasadas em autores como Nóvoa (2013), Josso (2010), Escolano (2017), Tardif (2012), e outros que discutem prática docente, cultura escolar e formação docente. Sobre os resultados obtidos, percebemos a relevância e influência das práticas das irmãs Militão, já que até aqueles que sofreram e condenavam os castigos físicos presentes, reconhecem a contribuição dessas professoras na educação bonfinense.
\end{abstract}

Palavras-chave: Professoras Leigas. Cultura Escolar. Prática Pedagógica. Facebook.

\begin{abstract}
The objective of this study is to analyze the pedagogical practices of the Sisters Militão, two lay teachers in the municipality of Senhor do Bonfim-BA. Based on the assumptions of Digital Public History under the basis of authors such as Carvalho (2016), Lima (2015) and Porto \& Santos (2014), we used as research source, comments presented in publications on Facebook. The analyzes were based on authors such as Nóvoa (2013), Josso (2010), Escolano (2017), Tardif (2012), and others who discuss teaching practice, school culture and teacher training. Regarding
\end{abstract}


the results obtained, we perceive the relevance and influence of the practices of the Militão sisters, since even those who suffered and condemned the physical punishment recognize the contribution of these teachers in the education of Bonfim.

Keywords: Lay Teachers. School Culture. Pedagogical Practice. Facebook.

\section{Apresentação}

A escolha do objeto de pesquisa se justifica por atenderem aos critérios estabelecidos pela pesquisadora, dentre eles a questão identitária como mulheres negras, e terem lecionado na segunda metade do século XX em Senhor do Bonfim, cidade onde ocorreu também a formação profissional da pesquisadora. As professoras Irmãs Militão, como eram populamente conhecidas, já falecidas, mantêm-se vivas nas memórias de moradores, ex-alunos e conhecidos, por motivos que vão desde a rígida disciplina e castigos físicos, ao amor e respeito presentes no processo de ensino-aprendizagem em geral.

Para a realização desse trabalho, optamos por utilizar como fontes de pesquisa, duas publicações sobre as Irmãs Militão na rede social Facebook, por considerar segundo Lima; Jaques; Ávila (2015), que a rede social constitui um espaço de narrativas biográficas e autobiográficas uma vez que tanto o dono do perfil quanto os indivíduos que escrevem os comentários exercem a escrita de si e ao mesmo tempo sobre o outro, portanto constitui um lugar de memórias. A definição do Facebook como fonte de pesquisa está embasada também na afirmação de Porto e Santos (2014, p. 16) de que "o Facebook hoje é a rede social que melhor caracteriza essas redes que passaram a fazer parte do cotidiano das pessoas". Além disso, de acordo com Santos (2017, p. 3), "os acervos pessoais virtuais se apresentam, assim como os cadernos e diários pessoais, como recursos no intento de guardar-se, perenizar-se e dar-se a ver na posteridade". E nesse intuito de guardar-se, perenizar-se e dar-se a ver na posteridade é que fazemos uso da História Pública Digital para darmos conta dos objetivos propostos nesse estudo, assim como respaldar o uso das fontes públicas digitais.

A partir de publicações feitas por dois perfis do Facebook, cujas iniciais são RA e MGP, sobre a atuação e importância das professoras Militão na educação e cultura de Senhor do Bonfim, analisamos os comentários feitos por usuários da rede que foram ex-alunos, ex-vizinhos e conhecidos das professoras, buscando identificar marcas da cultura escolar da época, a metodologia utilizada e as práticas disciplinares das Irmãs Militão.

O estudo foi realizado considerando os comentários publicados até o dia 20 de maio de 2020. Até essa data, a publicação do perfil de RA tinha 22 (vinte e dois) comentários e 75 (setenta e cinco) compartilhamentos, conforme podemos ver no print que segue (Antônio, 2019). 
Figura 1: Print de postagem de R. Antonio no Facebook

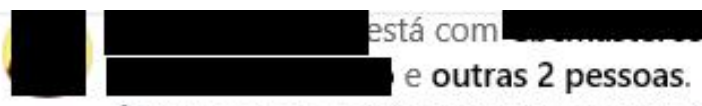

Administrador $\cdot 27$ de setembro de 2019 . 6

professoras irmãs Militão, de Senhor do Bonfim...Lembradíssimas pela "palmatória nossa de cada dia"

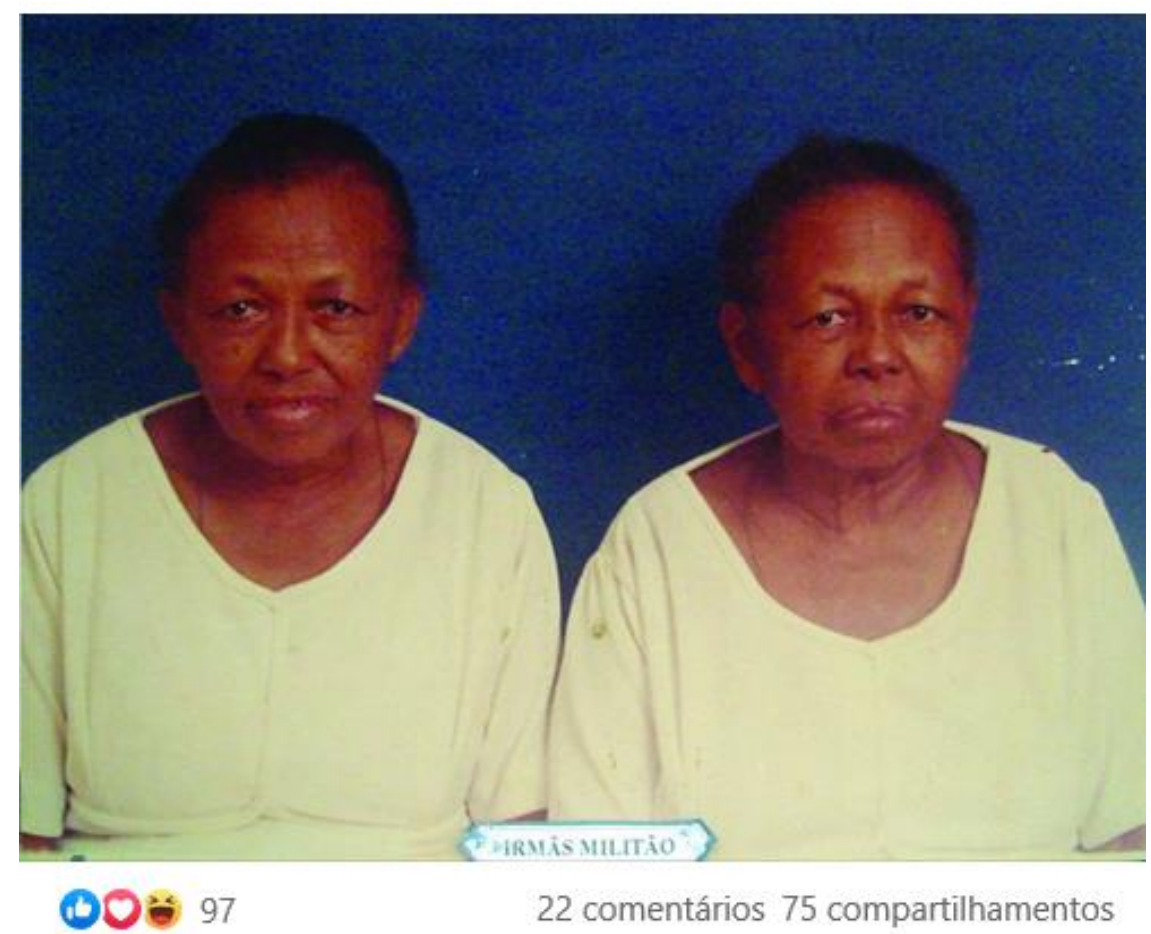

Fonte: https://www.facebook.com/groups/bahiaterradojateve/permalink/1332395210257722/.

Na publicação no perfil de MGP constavam 151 (cento e cinquenta e um) comentários e 229 (duzentos e vinte e nove) compartilhamentos. Segue o print do perfil analisado (Paz, 2015). 
Figura 2: Print de postagem de M. G. Paz no Facebook

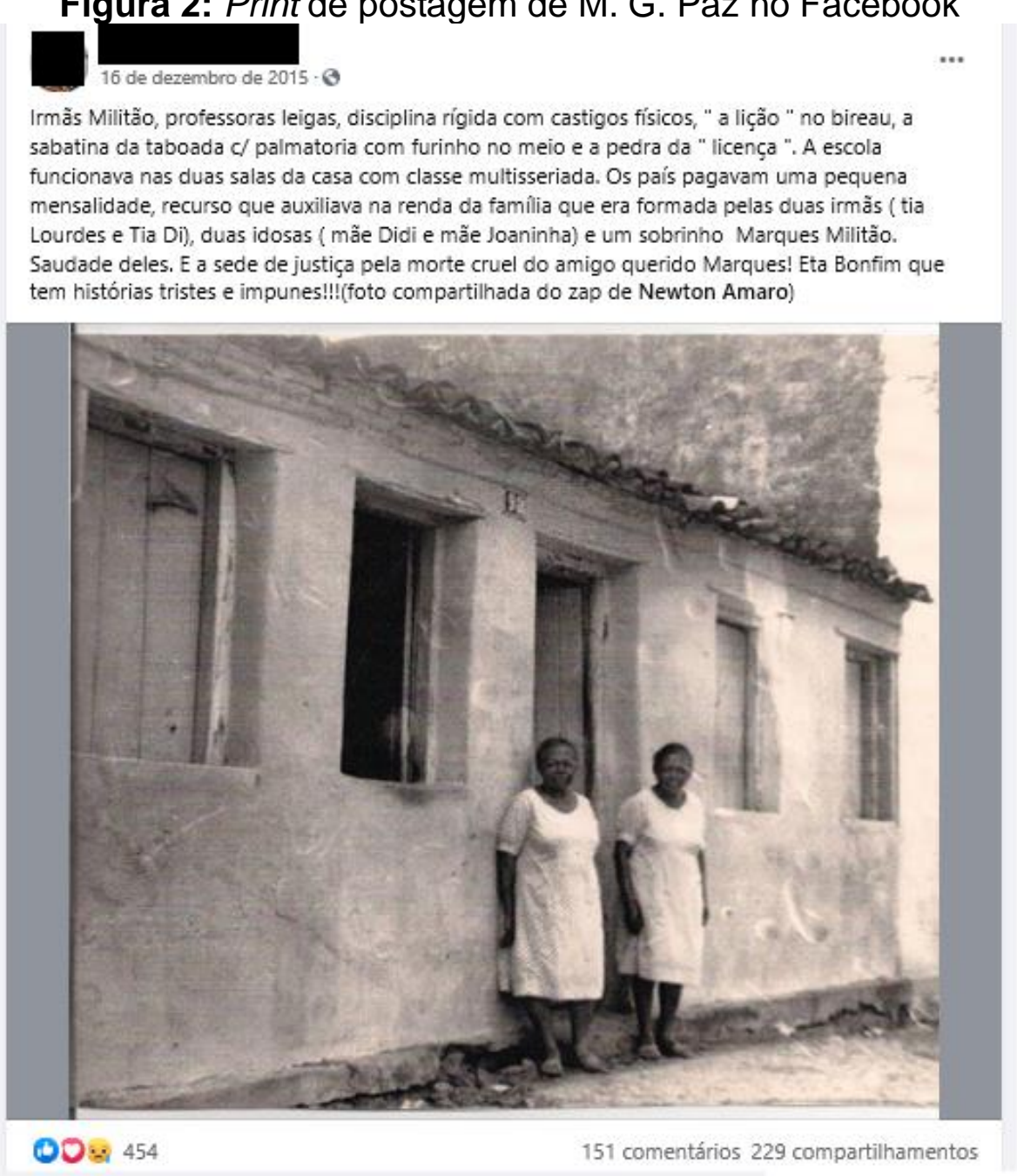

Fonte:

https://www.facebook.com/search/top/?q=irm\%C3\%A3s\%20milit\%C3\%A3o\&epa=SEARCH_BOX

Cada publicação é composta pelo texto escrito pelo autor de cada perfil, as fotografias das professoras e os respectivos comentários, cuja autoria varia de exalunos, vizinhos, conhecidos, familiares de ex-alunos e pessoas da atualidade que emitem opinião e/ou reproduzem histórias contadas por outros contemporâneos das professoras. O conteúdo do texto que apresenta cada perfil já nos fornece informações relevantes sobre a vida e práticas das irmãs Militão e nos instiga a ler e analisar os comentários fazendo-nos deduzir algumas situações e despertando a curiosidade sobre outros aspectos que nos faz compreender o papel desempenhado por essas professoras.

Além dos comentários presentes na rede social Facebook, usamos como bibliografia o trabalho de conclusão de curso (TCC) a nível de graduação, intitulado "Irmãs Militão: cotidiano, práticas e o funcionamento de uma casa-escola em Senhor do Bonfim de 1975 - 1985", cuja autoria é de José Roberto Amorim da Silva Peixoto, graduado em História pela Universidade do Estado da Bahia- Campus IV/Jacobina em 2014, morador de Senhor do Bonfim e que conviveu na infância frequentando a casa-escola das Irmãs Militão. Vale acrescentar que esse TCC tem grande importância para a pesquisa em desenvolvimento por fornecer pistas, mencionar pessoas e acontecimentos bastante relevantes para o processo investigatório. Através desse trabalho, algumas dúvidas foram esclarecidas e caminhos foram 
apontados assim como os rastros e indícios necessários e inerentes à pesquisa, conforme defende Guinzburg (2007).

Para explicitarmos o que nos propomos, o texto encontra-se dividido em 4 (quatro) partes, sendo a primeira parte a introdução que identifica o objeto de pesquisa, nossas pretensões, as fontes e o caminho metodológico utilizado; a segunda com o subtítulo "O ritual pedagógico da casa-escola das Irmãs Militão" identifica as professoras e a casa-escola assim como o seu funcionamento cotidiano; a terceira está denominada como "A prática pedagógica das Irmãs Militão; ora respeito e disciplina, ora castigos e medo", que dá ênfase aos principais procedimentos metodológicos efetivados pelas Irmãs Militão no processo de ensinoaprendizagem; e a quarta e última parte, constitui algumas considerações sobre o uso das redes sociais como fonte de pesquisa, as práticas das professoras Irmãs Militão e o papel que elas assumem na memória coletiva local, sobretudo para a educação e cultura do município de Senhor do Bonfim.

\section{O ritual pedagógico da Casa-Escola das Irmãs Militão}

"Quem não aprendesse com as Irmãs Militão, não aprenderia com mais ninguém..." Eis a mensagem que ecoa nas falas de muitos moradores do Município de Senhor do Bonfim, no interior da Bahia, quando se trata da história da educação, e especificamente dos professores que atuaram na segunda metade do século $X X$.

As professoras sujeitos desta pesquisa, conhecidas popularmente por irmãs Militão, tinham como nome de batismo - já que estamos falando de mulheres com fortes práticas religiosas no catolicismo - Maria de Lourdes Gonçalves Militão (1916 - 2002) e Maria Floripes Gonçalves Militão, cujas datas de nascimento e óbito estão sendo investigadas pela pesquisadora. As duas professoras eram chamadas carinhosamente por Tia Lourdes e Tia Di, respectivamente.

As irmãs Militão eram professoras negras, leigas e residiam em Senhor do Bonfim (BA) com alguns familiares. O núcleo familiar era formado a princípio pelo pai, a mãe, as duas irmãs e mais tarde um sobrinho muito querido e popular que foi brutalmente assassinado, conforme consta nas fontes.

Durante parte da vida adulta, após a morte do pai, as irmãs Militão transformaram a própria residência em uma escola nomeada Escola Santa Teresinha, a qual até o presente momento não localizamos documentação oficial, e que era conhecida por todos como Escola das Militão, sobrenome das professoras. A escola constituiu o meio de sustento da família após a morte da figura paterna e para isso era cobrada uma pequena mensalidade aos pais dos alunos, além da venda de doces e lanches no horário do intervalo como merenda escolar.

Segundo Peixoto (2014), a escola foi fundada na década de 1950 e funcionou até meados da década de 1980. A casa era localizada no centro da cidade, mais precisamente na Rua Rui Barbosa, onde atualmente funciona um supermercado. $O$ período de funcionamento nos dá a certeza de bastante tempo de funcionamento e, portanto da ação das professoras.

As irmãs Militão adquiriram uma certa fama na região que sobrevive nas memórias dos moradores atuais, por ter como característica principal a rigidez e disciplina severa com os alunos, entre outras especificidades ligadas às histórias de vida das professoras, conforme descreveremos no desenvolvimento do texto. 
Como professoras leigas, ou seja, não tinham a formação específica para atuar no Magistério, as irmãs Militão, segundo relatos, não deixavam a desejar quanto aos conteúdos curriculares, disciplina e orientações para a vida em geral, sendo consideradas por muitos como autodidatas por dominarem conteúdos sobretudo de Língua Portuguesa e Matemática.

Diante da falta de escolas públicas com vagas suficientes para atender as camadas populares, a existência das casas-escolas no município era algo comum. Por serem bastante humildes e oriundas também de casas-escolas, as irmãs Militão, após o falecimento do provedor da família e diante da escassez de recursos financeiros, resolveram transformar a própria residência em uma casa-escola, conforme consta no trabalho de Peixoto:

\begin{abstract}
Ela surge primeiramente com o objetivo de ser mais um meio de sustento da família Militão, devido à falta de recursos financeiros que fora provocada pela morte do chefe da família e a criação da casa-escola foi a única alternativa de ocupação remunerada, aconselhável para duas moças humildes e de boa família, mas com baixa escolaridade. A fundação da Escola Santa Terezinha, ao longo do tempo foi assumindo uma importância para a educação de Senhor do Bonfim, que chegou muito além do que uma mera fonte de renda para a família das suas fundadoras. Ela aos poucos passou a atender uma clientela muito diversificada da que a maioria das casas-escolas acolhia. Sua demanda advinha de diversas famílias e classes sociais, eram filhos de famílias ricas, bem como de núcleos familiares paupérrimos, sendo que, os primeiros estavam ali devido à inadequação disciplinar e pedagógica às estruturas de ensino ao qual o poder financeiro de suas famílias podiam Ihes garantir. (Peixoto, 2014, p. 24).
\end{abstract}

No entanto, conforme consta no relato acima, a escola Santa Terezinha tinha um diferencial em relação a tantas outras que existiram no município de Senhor do Bonfim. Havia uma diversificação no tocante a origem social dos estudantes, tendo alunos pobres e outros filhos de famílias mais abastadas. Essa diversificação aconteceu devido a fama da escola em termos de rigidez e disciplina com os alunos, que devido ao mal comportamento não eram aceitos nos estabelecimentos oficiais de ensino.

A famosa rigidez das irmãs Militão chegou ao ponto de servir de argumentos para os pais ameaçarem os filhos que demonstravam pouco interesse nos estudos, fazendo com que muitos estudassem temendo em ser matriculados na Escola Santa Terezinha, conforme o comentário de SMMS ao afirmar que "[...] todas as crianças tinham medo quando diziam em casa, vai estudar nas MILITẪO. Eu mesma fui uma!!!!". Comentários como esse demonstram que apesar da interlocutora não ter estudado com as irmãs Militão, tinha muito medo, e enfatiza isso até mesmo através da escrita na rede Facebook, fazendo uso de letras em caixa alta para se referir ao nome das professoras e sinais de exclamação, além do teor do comentário em si.

Vale lembrar que apesar dos castigos físicos terem sido abolidos legalmente no século XIX, na prática eles perduraram por longos períodos e foram motivos de muitas discussões e divergências entre diferentes grupos sociais. Para muitos docentes e até pais de alunos, o uso de castigos era recorrente no processo de ensino-aprendizagem e na garantia da autoridade do professor. Assim, mesmo com a proibição através de documentos oficiais, muitos professores levaram essa prática adiante e ainda com o consentimento dos pais conforme a citação que segue: 
Os pais utilizavam-se dos castigos corporais na educação doméstica, e entendiam a escola como uma continuação da casa, e desejavam que os professores continuassem castigando os alunos. Alguns descontentes com a intromissão do Estado em proibir os castigos nas escolas chegaram a autorizar por escrito a escola e o professor a continuar fazendo uso dos castigos corporais, entendendo que o direito dos pais em decidir a maneira como educar se sobrepõe a vontade do Estado (Lemos, 2011, p. 633).

Diante dessa afirmativa e considerando que as casas-escolas não eram estabelecimentos oficiais, podemos compreender a existência dos castigos físicos, como o uso da palmatória na rotina pedagógica da Escola das Militão em plena segunda metade do século $X X$.

Além do uso das punições para manter o controle e a disciplina dos alunos, outros saberes e crenças herdadas da sociedade em geral e de estruturas familiares constituíam a cultura escolar da escola das Militão, uma vez que estavam incorporadas nas estratégias de ensino e nas diversas formas de aprendizagem conforme indica Escolano:

A cultura da escola, nessa perspectiva de análise baseada na lógica da prática, é uma cadeia de rituais interativos, imersa por sua vez, no arquipélago dos ritos, que se insere no mundo da cotidianidade, seu contexto. (Escolano, 2017, p. 77).

Ainda sobre a prática escolar, o mesmo autor afirma que "os ritos não apenas cumpriram um papel funcional na vida das escolas, mas também uma finalidade antropológica e cultural". Essas finalidades antropológicas e culturais são perceptíveis ao analisarmos todo o funcionamento da escola das Militão, desde a estrutura física, o mobiliário e as práticas cotidianas.

Sobre a estrutura física da Escola das Militão, tratava-se de uma construção simples para fins residenciais, mas que devido a finalidade educacional que the foi atribuída, ganhou características de uma escola, não pelo espaço físico, mas pela presença do mobiliário e objetos semelhantes aos dos estabelecimentos de ensino. A seguir, apresentamos a estrutura física da casa-escola Santa Terezinha, conforme a descrição feita por Peixoto (2014):

Era uma pequena casa construída com paredes de adobe e coberta com telhas de barro rústico, bem ao estilo das construções do início do século $\mathrm{XX}$, com paredes caiadas na cor amarela ou branca e um rodapé em vermelho. Possuía um conjunto de quatro janelas em madeira de umburanas, separadas em pares por uma porta frontal. Havia ainda dois quartos que serviam de alojamento para as mestras e sua mãe, duas salas onde funcionavam as classes diuturnamente e a cozinha, contando também, com um banheiro que apesar de ser bastante asseado, possuía uma latrina com as chamadas fossas negras e um quintal bem amplo, repleto de árvores frutíferas. O piso era de cimento em tom vermelho e a cozinha contava com um compartimento de abertura ampla para o quintal, onde funcionava um belo fogão a lenha. Um pouco afastado ficavam os potes com água e na sala um filtro com uma bandeja de copos coberta com panos alvíssimos. A mobília era bastante simples e rústica. (Peixoto, 2014, p. 28). 
$\mathrm{Na}$ descrição acima, percebemos apenas características de uma casa residencial simples, comum e que o autor faz questão de enfatizar a higiene do ambiente, usando adjetivos como asseado ao se referir ao banheiro, e alvíssimos ao se referir aos panos que cobriam os copos.

Podemos inferir que tais características agregavam valor ao espaço e consequentemente às pessoas que geriam o mesmo, qualificando ainda mais a função que exerciam de educar, pelo fato de demonstrarem zelo e organização no ambiente. Além disso, devemos considerar que apesar de ser uma residência, o ambiente tinha em suas peculiaridades, características e signos que explicitavam e justificavam as ações educativas que aconteciam naquele local. Tudo era organizado de forma que as intenções culturais e pedagógicas fossem percebidas por aqueles que ali frequentavam, constituindo à arquitetura da escola das irmãs Militão. Segundo Escolano (2001, p. 33), a arquitetura escolar é um elemento cultural e pedagógico, não só pelos condicionamentos que suas estruturas induzem, mas também pelo papel de simbolização que desempenha na vida social. Assim, a localização e a organização da escola Santa Terezinha estavam intrínsecas às atividades que ocorriam ali.

Ainda falando da espacialização da casa-escola das irmãs Militão, podemos notar a seguir que o ambiente ganha características escolares através da existência e disposição do mobiliário.

Na primeira sala, encontravam-se carteiras individuais e duplas, dispostas em fila indiana e logo à frente, um grande quadro negro apoiado sobre um grande baú de madeira ao lado da carteira da mestra. Sem esquecer uma velha cadeira de balanço usada por mãe Didi situada na entrada da casa, onde, de lá controlava a chegada e a saída dos meninos e meninas. (Peixoto, 2014, p. 28).

$\mathrm{Na}$ descrição da segunda sala, por conta dos utensílios e mobiliários em geral, percebemos a mistura de características entre uma casa residencial e ao mesmo tempo uma escola, da mesma forma que podemos inferir sobre alguns hábitos e crenças religiosas das irmãs Militão. Essas últimas eram muito valorizadas socialmente diante da tradição do povo que iam em busca do trabalho educativo desenvolvido pelas irmãs Militão.

\begin{abstract}
A segunda sala era organizada da seguinte forma: possuía uma grande mesa servida de compridos bancos e tamboretes, e um pouco mais afastado uma pequena mesa assistida por um caixote, que era utilizada pelas mestras para tomar a lição dos alunos. Alguns desses alunos afirmavam que a mobília era muito desconfortável, mas evitavam reclamar por medo do castigo. Facilmente se encontravam nessas salas, outras mobílias que faziam parte da vida doméstica da casa, bem como o rádio, o televisor, as cristaleiras, tripés de panelas, porta retratos e um pequeno altar com as imagens de sua devoção. (Peixoto, 2014, p. 29).
\end{abstract}

Em relação aos horários das atividades da escola, sabemos que funcionava a princípio nos turnos matutino e vespertino, e depois, com a criação do Movimento Brasileiro de Alfabetização-MOBRAL, em 1968, as irmãs Militão passaram a lecionar também no turno noturno para alfabetizar alunos adultos. 
Sobre a rotina da escola, é interessante mencionar o cumprimento de horários de entrada e saída, de aulas e de intervalo semelhante aos estabelecimentos oficiais de ensino. Além disso, fazia parte da rotina da escola das Militão, a averiguação da higiene pessoal dos alunos, conforme Peixoto (2014) descreve sobre o funcionamento da escola no turno matutino.

Pela manhã, a porta se abria às 07 horas e 30 minutos quando iniciava a revista minuciosa das condições de higiene pessoal de cada aluno, ao término da recepção, as aulas começavam pontualmente às 08 horas e se prolongavam até 12 horas, com uma parada para a merenda às 10 horas recomeçando as atividades em classe às 10 horas e 30 minutos. (Peixoto, 2014, p. 29).

Além da atenção dada à higiene pessoal dos alunos, outros aspectos ligados à convivência social, educação doméstica, religiosidade e ludicidade também faziam parte do ofício de ensinar das professoras Tia Di e Tia Lourdes, as irmãs Militão, uma vez que essas vivências eram incorporadas no trabalho pedagógico constituindo os saberes experienciais e culturais, conforme classifica Tardif (2012).

No próximo tópico, discutiremos sobre as práticas efetivadas pelas irmãs Militão, práticas essas que nos mostram o porquê da imortalidade do nome e função dessas educadoras, assim como da contribuição dada por essas mulheres na educação e cultura do município de Senhor do Bonfim-BA.

\section{As práticas pedagógicas das Irmãs Militão; ora respeito e disciplina, ora castigos e medo}

As irmãs Militão montaram a estrutura de funcionamento de sua casa-escola tomando como base o modelo em que também aprenderam a ler e escrever, ou seja, em casas-escolas com outras professoras, também leigas que se valiam de castigos físicos para ensinar e manter a disciplina dos alunos. Complementando e dando características próprias ao modelo pedagógico das irmãs Militão estavam os diversos saberes inerentes às suas vivências como mulheres atuantes e possuidoras de saberes, crenças e habilidades que iam do ler e escrever, aos afazeres domésticos, rituais religiosos e comemorações culturais, que, de acordo com Tardif podemos classificar da seguinte forma:

Os professores, em suas atividades profissionais se apoiam em diversas formas de saberes: o saber curricular, proveniente dos programas e dos manuais escolares; o saber disciplinar, que constitui o conteúdo das matérias ensinadas na escola; o saber da formação profissional, adquirido por ocasião da formação inicial ou contínua, o saber experiencial, oriundo da prática da profissão, e, enfim, o saber cultural, herdado da sua trajetória de vida e de sua pertença a uma cultura particular, que eles partilham em maior ou menor graus com os alunos. (Tardif, 2012, p. 297).

De acordo com essa classificação de saberes e considerando que as Irmãs Militão eram professoras leigas, podemos inferir que a base de suas práticas 
pedagógicas estava nos saberes disciplinar, experiencial e cultural. No entanto há relatos que as professoras seguiam os conteúdos exigidos para os testes de admissão da época, o que também nos faz inferir que tinham acesso aos programas e manuais escolares, mesmo que fosse na informalidade, através da rede de contatos com algumas professoras normalistas da época.

A diversidade de saberes atrelada à disciplina rígida e ao carisma/simpatia das Irmãs Militão proporcionaram o reconhecimento e respeito aos feitos dessas duas mulheres professoras ao mesmo tempo que causou também muito medo em crianças que estudaram com elas ou que temiam em estudar e seguiam fielmente as orientações dos pais para evitar serem matriculados na escola das Militão. A seguir, temos o depoimento de Peixoto (2014), demonstrando as impressões que teve ao conhecer, quando criança, a escola das Militão.

Ao chegar, percebi que não se tratava de uma escola comum, pois todos os alunos, ao entrar, pediam a benção às professoras, que apesar do comportamento rígido, eram bem agradáveis...Foi uma surpresa estar ali, pois aquela escola era "sinônimo de terror" para meninos travessos da época, apelidada popularmente de "Escola Reformatório Pedra Preta" por causa da larga utilização da palmatória como instrumento disciplinador. (Peixoto, 2014, p. 10).

Ao analisar os comentários encontrados nas duas publicações do Facebook, percebemos que as impressões de Peixoto (2014) sobre a escola das Militão não são isoladas. Elencamos as categorias medo, respeito, amor, saudade, gratidão e recordação considerando que "todo relato é, por definição, interpretativo, e que uma grande parte do nosso trabalho de análise consistirá em descobrir e desvelar as pré-interpretações, contidas nas descrições de fatos" (Josso, 2010, p. 78).

Apesar da dificuldade em compreender e identificar o significado de cada comentário, foi possível fazer a seguinte classificação: 60 (sessenta) comentários relatam a recordação de um fato ou emitem opinião sem demonstrar um sentimento específico; 34 (trinta e quatro) comentários fazem referência ao medo dos castigos físicos presentes na prática pedagógica das irmãs Militão; 16 (dezesseis) comentários demonstram gratidão ao trabalho das professoras; 15 (quinze) comentários são demonstrações de saudade das mestras; 14 (catorze) comentários são declarações de amor por Tia Lourdes e Tia Di; 13 (treze) comentários fazem referência ao respeito às professoras e suas ações.

A análise nos mostra uma mistura de sentimentos e recordações saudosas, muitas vezes adversas, no entanto predominando o reconhecimento pelas ações educativas e culturais desenvolvidas pelas irmãs Militão, que nos faz inferir que o medo, ódio, desespero e os diversos comentários negativos sobre a rigidez e os castigos físicos são oriundos do imaginário de pessoas que não estudaram ou frequentaram a casa-escola das irmãs Militão.

Concluimos isso ao analisarmos os comentários de ex-alunos e pessoas mais próximas, principalmente os vizinhos, que mesmo quando afirmam terem sentido medo das práticas disciplinares, também demonstram sentimentos de respeito, saudade, gratidão, amizade. Vale enfatizar que essas práticas disciplinares, eram rígidas e explicitamente demonstradas através de castigos físicos com o uso da palmatória, sendo esses últimos com o conhecimento e consentimento dos familiares dos alunos. 
Seguem alguns comentários que nos mostram essa mistura de medo, amor, respeito, saudade e gratidão. Ressaltamos que a grafia original e pontuação dos comentários foram mantidas, e os usuários autores estão identificados pelas iniciais:

\begin{abstract}
Cresci com esse alerta: senão estudar direito, vai aprender com "as militaos" Na palmatória! Mas as minhas breves lembranças delas, era de uma simpatia. Passava sempre na casa delas em minhas visitas a casa do meu avô, vizinho a elas. (grafia do autor, BMP).

Aff!!!! Como não lembrar. Éramos vizinhos e meus pais tinham grande amizade por elas. Na Infancia estudei comas duas tias e lembro muito bem das sabatinas que eram feitas e quando não acertava a taboada era bolo de palmatoria na certa, Bons tempos. (grafia do autor, AC).

Estudei lá e apanhei muito na sabatina da tabuada. Lá aprendíamos na "marra" e a disciplina era rígida. Ainda sinto o sabor do mingau de milho que elas vendiam no recreio. Era feito num velho fogão a lenha. Lembro-me bem do $P$ (irmão do J R) na janela cantando uma paródia com tia Di e ela correndo para a janela a reclamar. O Santo Antonio e a "lapinha" delas também eram famosos. Bons tempos. (grafia do autor, MLG).
\end{abstract}

As opiniões e sentimentos divergem. No entanto é perceptível que poucos são os comentários de pura reprovação aos castigos físicos aplicados. Além disso, reafirmamos que esse tipo de comentário são de pessoas que não estudaram na escola das Militão, mas que ouviam falar da existência de castigos, como podemos perceber na fala de EB ao afirmar que "Quando eu ouvia falar dessas irmãs Militão eu me acabava de medo. Kkkk" ou ainda de MCSR ao dizer "Passava por lá e morria de pena dos alunos!!!Eu já tinha nas veias a pedagogia do afeto".

Aqueles que frequentaram a escola, mesmo reconhecendo a existência dos castigos, como o uso da palmatória, por exemplo, tiveram a oportunidade de usufruir de outras práticas que amenizavam o medo e despertavam sentimentos de afeto transformados em saudade com o passar do tempo. Vejamos:

Eu lembro claramente da fisionomia delas!!! Me pelava de medo da tia $\mathrm{Di}$... a tia Lourdes era mais amável, menos rígida!!! Sempre debruçada na janela ja esperando a gente tomar a bênção. Rarsss $\mathrm{Hj}$ entendo as grandes mulheres que foram! Saudades... (grafia do autor, BJ).

Ou ainda:

Que saudade nossa! Eu e meu imao mais velho tivemos o prazer de ser alunos dessas duas senhoras. Mas confesso que sofrir um pouco com o jeito delas ensinarem.levei muitas palmadas na palma da mão.e até. Hj me lembro do mingau que elas faziam com fubá de milho na hora do recreio. kkkkkk (grafia do autor, MKD).

Sobre a diversidade de práticas e saberes que faziam parte do cotidiano daqueles que frequentavam a casa-escola das irmãs Militão, afirmamos que era fator essencial nas relações de respeito e consideração pelas professoras, pois estas encantavam a todos e se faziam reconhecidas a partir de suas práticas 
educativas embasadas em suas vivências e trajetórias ligadas à religiosidade, crenças, cultura popular e convivência social, conforme percebemos no relato de ES, ao revelar: "Eu tive uma filha alias dei a luz a uma filha com a Lourdes me ajudando... (grafia do autor)" Ou ainda em "Como não lembrar destas criaturas!! das suas vozes grossas e rudes!das suas religiosidades!!!!que iam dos carurus, a sua imponente lapinha!!!! Eitha infância cheia de emoções e saudades [...]. (grafia do autor, JM).

Percebemos também que muitos moradores recordam com saudade inclusive da rígida disciplina e castigos físicos, motivados pela insatisfação com o funcionamento da educação em geral na atualidade, atribuindo os casos de violência e indisciplina existentes em muitas escolas, à falta de práticas severas de disciplina como os castigos físicos. Essa afirmativa é elaborada baseada em comentários como o de YSJ ao afirmar que "Se as escolas hoje fossem iguais a essa, jamais teria tanta falta de respeito com professor como existe hoje."

Diante do exposto, notamos que as opiniões divergem bastante, mas apresentam um ponto semelhante salvo raras exceções e por motivos já explicitados: as irmãs Militão eram temidas, porém respeitadas por muitos e permanecem vivas na memória local diante de práticas educativas que extrapolavam os conteúdos de Língua Portuguesa e Matemática e adentravam em conhecimentos ligados às normas sociais, ao lazer, à cultura e afazeres que tornaram-nas em protagonistas na história da educação e cultura do município de Senhor do Bonfim, apesar da condição de professoras leigas.

\section{Algumas considerações}

Sobre o objeto de pesquisa específico desse estudo foi possível descobrir e analisar informações, acontecimentos e práticas da vida cotidiana e profissional das professoras estudadas que justificam o fato delas continuarem tão vivas na memória da população, servindo inclusive de referência como educadoras para as séries iniciais, apesar de não terem em sua trajetória a formação específica para o Magistério.

Dessa forma, é relevante mencionar os numerosos indícios sobre tantas outras memórias ligadas à educação local e regional que despertam a curiosidade do leitor, sobretudo pesquisadores /historiadores, podendo gerar outras pesquisas na área da História da Educação. Além disso, foi possível verificar o papel assumido pela rede social Facebook como espaço memorialístico através dos diversos elos que se estabelecem de forma rápida e com um grande número de usuários permitindo a composição de histórias como as das professoras irmãs Militão e outras afins, contribuindo para a pesquisa de doutorado e outras que podem ser desenvolvidas em outro momento e/ou por outros pesquisadores.

Nesse estudo específico, identificamos sujeitos que consideram as antigas práticas efetivadas pelas professoras como traumáticas, devido ao uso de castigos físicos, mas que também se recordam com saudades de outros ensinamentos no âmbito cultural desenvolvidos pelas irmãs Militão que precisam ser lembrados e valorizados.

Com as fontes utilizadas foi possível analisar a prática pedagógica das professoras, identificar as diversas atividades que elas desenvolviam no campo religioso e cultural, como por exemplo, o caruru de Cosme e Damião, as novenas 
de Santo Antônio, auxiliar mulheres em trabalho de parto, etc., e a influência dessas atividades no desenvolvimento do respeito e prestígio como educadoras, assim como as possíveis explicações para a presença de sentimentos como amor e ódio, medo e respeito e outros tantos demonstrados das mais diversas formas nos comentários analisados.

Assim, percebemos com esse estudo, o quão se faz necessário, nós pesquisadores da educação nos debruçarmos cada vez mais sobre como se constitui o ofício de ensinar, suas causas, formas e consequências, dando a devida importância à formação e atuação do professor e a relação com as suas histórias de vida, já que segundo Nóvoa (2013, p. 17), "é impossível separar o eu profissional do eu pessoal". Percebemos ainda a importância de adentrarmos sobre a história da educação local, estabelecendo relações com a regional e nacional e dando visibilidade a história contada de baixo, conforme nomeia o historiador Thompson, que é aquela construída e contada por indivíduos comuns, pertencentes às classes consideradas subalternas, que não aparecem na história oficial, mas que constituem sujeitos sociais, atores dos acontecimentos passados, e que são de extrema necessidade para a compreensão e transformação da realidade.

Portanto, as professoras irmãs Militão, Tia Lourdes e Tia Di, com as diversas funções que assumiram ao longo da vida, como educadoras, merendeiras, benzedeiras, parteiras e tantas outras experiências vivenciadas, sem dúvida, contribuíram com a educação e a cultura do Município de Senhor do Bonfim, no Sertão do estado da Bahia e são merecedoras de reconhecimento na Historiografia e na História da Educação local.

\section{Referências}

Antõnio, R. Professoras irmãs Militão, de Senhor do Bonfim...Lembradíssimas pela "palmatória nossa de cada dia". Senhor do Bonfim, 29 set. 2019. Facebook. Disponível em:

https://www.facebook.com/groups/bahiaterradojateve/permalink/133239521025772 2/. Acesso em 29 de set 2019

Carvalho, B. L. P. (2016). História Pública e Redes Sociais na Internet: elementos iniciais para um debate contemporâneo. Revista TransVersos, 7(7), 35-53.

Escolano, Agustín. (2017). A Escola como cultura: experiência, memória, arqueologia. Ed. Alínea.

Escolano, Agustín. (2001). Arquitetura como programa. Espaço-escola e curriculo. In Vinão, A. Frago; Escolano, A. Currículo, espaço e subjetividade: a arquitetura como programa. 2. ed. Rio de Janeiro: DP\&A. 2001, p. $19-58$.

Lemos, D. C. D. A. (2012). Os cinco olhos do diabo: os castigos corporais nas escolas do século XIX. Educação \& Realidade, 37(2), 627-646. Disponível em: http://www.ufrgs.br/edu_realidade Acesso em 10 de dez de 2019. 
Lima, M. T., Jaques, K. M., \& Ávila, T. M. (2015). Facebook-Um novo espaço autobiográfico?. Letras \& Letras, 31(1), 282-298.

Ginzburg, Carlo. (2007). O fio e os rastros: verdadeiro, falso, fictício. São Paulo: Companhia das Letras.

Josso, Marie-Christine. (2002). Experiências de vida e formação. Lisboa: Educa. Nóvoa, Antonio (org.). (2013). Vidas de professores. Porto: Porto.

Paz, M. G. Irmãs Militão: professoras leigas, disciplina rígida com castigos físicos, "a lição" no bireau, a sabatina da taboada com palmatória com furinho no meio e a pedra da "licença". Senhor do Bonfim, 16 dez. 2015. Facebook. Disponível em: https://www.facebook.com/search/top/?q=irm\%C3\%A3s\%20milit\%C3\%A3o\&epa= SEARCH_BOX. Acesso em 30 set. 2019.

Peixoto, J. R. A. S. (2014). Irmãs Militão: cotidiano, práticas e o funcionamento de uma casa-escola em Senhor do Bonfim de 1975 - 1985. 2014. Monografia (Licenciatura em História). Universidade do Estado da Bahia, Campus IV. Jacobina-BA. Disponível em: www.saberaberto.uneb.br/handle/20.500.11896/729. Acesso em 14 de nov de 2019.

Porto, C.; Santos, E. (orgs). (2014). Facebook e Educação: publicar, curtir, compartilhar [online]. Campina Grande: EDUEPB. Disponível em: https://static.scielo.org/scielobooks/c3h5q/pdf/porto-9788578792831.pdf. Acesso em 10 de abril de 2020.

Tardif, Maurice. (2012). Saberes docentes e formação profissional. 13. ed. Petrópolis, RJ: Vozes. 